\title{
CONSOLIDATION IN PRIMARY PULMONARY TUBERCULOSIS
}

\author{
BY \\ D. ADLER AND W. F. RICHARDS \\ From High Wood Hospital, Brentwood, Essex
}

(RECEIVED FOR PUBLICATION FEBRUARY 3, 1953)

The occurrence of large radiological opacities in the lung parenchyma in cases of primary tuberculosis has been recognized since Eliasberg and Neuland (1920) described a dense shadow, occurring usually in the right upper lobe, in young children with a primary infection. They stated that the onset was not acute, the course was benign, and that tubercle bacilli were not recoverable from the sputum. In a second paper (1921) they differentiated the condition from caseous pneumonia, but made no mention of atelectasis. They suggested that the term " epituberculosis" be applied to the condition.

Since the publication of these papers there has been considerable controversy over the condition. The following theories as to its pathology and pathogenesis have been evolved.

\section{Theories of Pathology and Pathogenesis}

AteleCtasis.-Producing a large homogenous opacity of segmental or lobar distribution, which clears on subsequent re-expansion or re-aeration, atelectasis has been held by many authorities to explain sufficiently the radiological and clinical course of epituberculosis. Morlock and Pinchin (1933) described the case of a boy of 14 in whom atelectasis of the right upper lobe expanded after removal of part of an enlarged, caseating lymph gland at bronchoscopy. This must be the earliest account of bronchoscopic appearances in primary pulmonary tuberculosis. Lightwood and Wilson (1936) gave an account of a boy of 5 in whom an atelectatic left lung was resected; there was gross bronchiectasis, but in some areas there was a granulomatous condition of tuberculous origin which might have been capable of resolution. Kent (1942), Jones, Rafferty, and Willis (1942), and Graham and Hutchison (1947) from bronchoscopic and bronchographic studies in their various series came to the conclusion that epituberculosis was, in fact, pulmonary collapse due to bronchial occlusion.

In our view atelectasis alone must be associated with reduction in volume of the affected area, although atelectasis and consolidation may coexist, giving rise to a condition of collapse-consolidation.

Non-TUberculous PNeumonia.-Eliasberg and Neuland (1920) doubted that the consolidation they described was a true tuberculous process. Engel (1921) noticed the absence of tubercles in the consolidated area at necropsy and suggested the term " para-tuberculosis," as in his opinion it was not a true tuberculous process. Winkler, quoted by Reichle (1933), thought that tuberculosis lowered the resistance of the neighbouring lung tissue to other organisms. Pinner (1945) came to the conclusion on clinical observation that bronchial occlusion did not produce atelectasis but a benign physiological consolidation of the lung distal to it. Pyogenic infection of a collapse resulting from primary infection is a well-known late complication (Brock, 1950), and pus behind a bronchial stenosis can produce the radiological picture of consolidation. This complication can also occur during the active phase of the primary complex, but is a comparatively rare event, occurring in our experience in $3 \%$ of cases with bronchial obstruction.

Resolvable Tuberculous Consolmation.-As the condition is a benign process, necropsy findings elucidating the pathology are comparatively rare, and are open to the objection that, as the subjects died, there is no certainty that the condition would have resolved. The same objection would apply to resection material. Rubinstein (1928), however, published the following case:

A girl aged 6 years had her fourteenth attack of " grippe"; a chest radiograph showed enlargement of the bronchial nodes, and a massive mediastinal shadow at the right root; the lung fields were normal. Two months later her condition became worse with pyrexia to $104^{\circ} \mathrm{F}$., and radiographs revealed a heavy shadow in the right middle lobe from the hilum to the periphery in addition to large hilar nodes. Empyema was suspected, and following an unsuccessful attempt at aspiration rib resection was performed, but no pus was found. There was a thickened pleura over a firm lung and biopsy was done to exclude a tumour. The specimen revealed histologically pulmonary consolidation, giant 
cells, epithelioid cells, lymphocytes, fibroblasts, and small areas of caseation; unfortunately staining for tubercle bacilli was not carried out. The child made a complete recovery, serial radiographs showing a gradual resolution of the opacity.

Necropsy findings reported on children who had died from accident, intercurrent infection, or tuberculosis of parts of the body remote from the lungs, usually meningitis, have revealed a closely similar histology (Armand-Delille and Lestocquoy, 1931 ; Reichle, 1933; Cameron and De Navasquez, 1936; Macgregor and Alexander, 1937; Fish and Pagel, 1938). Essentially there is consolidation with the alveolar spaces filled with epitheloid cells, and in the inter-alveolar tissues numerous Langhanstype giant cells, with a variable number of lymphocytes ana fibroblasts. Tubercle bacilli were not easily found in the consolidated lung itself; for instance, in the case reported by Cameron and De Navasquez (1936) the affected portion of the lung was negative on culture but positive on guinea-pig inoculation. Caseation when present was minimal in extent except in associated lesions such as a primary focus and in the regional bronchopulmonary glands, which were invariably enlarged and caseous.

It is probable that the underlying histology is not identical in all cases which run the typical clinical and radiological course of epituberculosis. Kayne, Pag:1, and O'Shaughnessy (1948) suggested three histological types: (1) a gelatinous pneumonia, rich in giant cells, the result of hypersensitive response to tuberculo-protein; (2) a tuberculous pneumonia, similar to that produced by the experimental intratracheal injection of tubercle bacilli in animals; (3) innumerable small granulomata.

Spence (1932) described a case in which he obtained caseous material by lung puncture over the affected area, which was positive to smear and guinea-pig tests; lung puncture repeated four weeks later at a different site was positive in smears. However, this boy, aged 7 months, ran a mild pyrexia, the radiographic shadow three months after admission was slightly diminished, but no further change was seen six months after admission when the boy was discharged. No account of a follow-up has been given, and he might possibly have been suffering from a caseous pneumonia. In this series in some cases which resolved large areas of consolidation were left with calcification of varying extent as evidence of previous caseation (see Figs. 5a, b). Bateman (1937) reported negative findings on lung punctures in typical cases.

Role of Bronchial Lesions.-That bronchial obstruction is a frequent complication of primary pulmonary tuberculosis is now well recognized (Jones and others, 1942; Richards, 1944a; Macpherson and Lutwyche, 1950). A tuberculous bronchopulmonary gland either compresses or erodes the affected bronchus. When there is radiological evidence of obstruction the tuberculous process has already perforated the cartilaginous and muscular wall of the bronchus in the majority of cases (Jones and others, 1942; Soulas and Mounier-Kuhn, 1949; Hutchison, 1949; Richards, 1952). Aspiration of caseous material containing tuberculo-protein and tubercle bacilli may follow perforation into the bronchial lumen. A frank bronchopneumonic type of tuberculous infiltration results occasionally from this incident, but in our experience rarely. Perhaps this is due to the paucity of viable tubercle bacilli in caseous material, as has been pointed out by Rich (1944), or an immunity of these subjects at this stage of the infection to this type of spread (Lange and Brunzema, 1930).

In the majority of post-mortem reports in these cases a bronchial perforation has been described. In two of Fish and Pagel's cases (1938) a caseous primary focus perforated into a bronchus instead of the more usual bronchopulmonary gland. In two cases reported by Armand-Delille and Lestocquoy (1931) no bronchial perforation was found, but in one there was histologically an area of atelectasis in the affected part of the lung. A resolving pulmonary consolidation can be produced in sensitized rabbits by the intratracheal injection of either live or dead tubercle bacilli; some of these experiments will be referred to later. Soulas and Mounier-Kuhn (1949) did not think that the perforation of a tuberculous gland played a significant part in the development of epituberculosis. They stated that the orifice of the bronchus to the affected part of the lung showed redness and oedema only and that epituberculosis was an early development in the primary infection and occurred before perforation took place.

ALLERGY.-Some forty years ago a common procedure in the diagnosis of a tuberculous joint was the injection of tuberculin subcutaneously; a focal reaction was produced, the joint becoming red, swollen, and tender. It was not uncommon in these cases to observe consolidated areas in the lungs coincident with the joint reaction. In discussing the potential dangers of Mantoux testing in the unstable case Lincoln and Grethman (1939) reported a haemorrhagic reaction round a caseous primary focus in the lung, two cases of meningitis, and two pleural effusions all occurring one to four days after the intradermal injection of 0.01 or $0.1 \mathrm{mg}$. 
of old tuberculin; in other cases phlyctens, erythema nodosum, a papulo-necrotic tuberculide, and enlargement of the tuberculous lymph nodes occurred. Langer (1923) reported the case of a boy who received $0.1 \mathrm{mg}$. of old tuberculin subcutaneously and subsequently developed a dense shadow over the whole of a lobe which resolved in 10 days.

Animal experiments have shown that allergy plays an essential part in the development of benign tuberculous pulmonary consolidations. Nichols (1905) produced in sensitized rabbits, by the intravenous inoculation of a virulent human strain of tubercle bacillus, a pulmonary consolidation which was well developed by the fifth day and had cleared by the thirtieth day, leaving a few scattered tubercles and no bacilli. The course was different in unsensitized animals similarly inoculated; these started a caseous pneumonia on the seventeenth day which was steadily progressive. From the foregoing it appears that the bronchial route of inoculation is not the only one capable of producing the condition.

Willis (1934) gave an account of the results of intratracheal inoculation of human and bovine strains of bacilli in sensitized rabbits. Consolidation of the lungs appeared in 48 hours and resolution was practically complete in 43 days. Necropsies revealed in the early -stages a firm, gelatinous consolidation with an increase in lung volume, and the presence of many epithelial cells; later giant cells appeared and there was a diminution of volume in the consolidated part of the lungs. Unsensitized control animals developed a progressive lesion which had a later onset. Oppenheimer (1935), using large doses of killed human type bacilli injected into the trachea of sensitized rabbits, produced a pulmonary consolidation in most of the animals. The resulting radiological opacity was maximal in two to four weeks, and then gradually cleared completely. No opacity occurred in unsensitized animals treated in the same way. Stained sections of the lungs in the first group revealed epithelioid and giant cells, lymphocytes and small areas of caseation varying in size in different animals; tubercle bacilli or their fragments could be seen as long as the radiological opacity persisted. Sensitized rabbits receiving live bacilli in the same doses developed a similar radiological shadow, but the condition progressed to a fatal termination. Oppenheimer quoted Rich as stating that the probable outcome of bronchial perforation in man depended on the numbers, viability, and virulence of the tubercle bacilli in the material discharged into the bronchus; small numbers of dead bacilli produced epituberculosis and large numbers of live bacilli caused caseous pneumonia. In these experiments there was considerable variation in the lesion produced in the lungs of sensitized animals varying from minimal histological evidence to moderate caseation. The sensitizing and subsequent intratracheal doses were measured and identical in each case, and therefore another factor which varied from animal to animal was present and affected the outcome.

It seems probable that a consolidation arising during the active phase of a primary tuberculous infection is modified both by the dose of tubercle bacilli, as suggested by Rich (1944), and by the degree of allergy of the individual. The resulting lesions will vary in severity and the amount of caseation present, the mildest being an epituberculous type of consolidation, the severest a modified granulocaseous pneumonia. Illustrating the latter type of lesion one of us (Richards, 1944b), in a series of 445 children with primary infection, reported seven deaths from granulocaseous pneumonia in children under 2 years. Three came to necropsy; the lungs and lobes affected proved to be solid masses of granulation tissue with little caseation.

\section{DiAgnosis}

A radiograph will not reveal the pathology of a consolidation. A similar picture is produced by an epithelioid consolidation, a granulo-caseous pneumonia, or a consolidation due to pyogenic organisms. The clinical onset may not be much help in the diagnosis, as in our experience it may be just as acute in the first of these conditions as in the last. Serial radiographs will show the slow progress of the tuberculous process, and the appearance of cavitation or areas of calcification will help to determine its type. A grossly positive sputum would suggest a caseous pneumonia. During the period covering this series no case of an extensive caseous pneumonia occurred in this hospital, otherwise cases of caseous pneumonia would have been included.

\section{DEFINITIONS}

In this report we have endeavoured to differentiate, on radiological evidence, between cases of pure collapse and atelectasis, which were excluded from our material, and consolidation both with and without associated collapse. The undermentioned definitions are a radiological description and do not refer to the underlying pathology.

Atelectasis.-Atelectasis is defined as homogenous opacity of segmental or lobar distribution with reduction in volume of the affected area of 
lung, the reduction being by at least one third (Robbins and Hale, 1945) of the expected normal volume.

CollaPSE.-The definition of collapse is the same as for atelectasis but without the homogenous character of the opacity.

Diagnosis in long-standing cases of collapse is often difficult, and often it cannot be definitely excluded on routine films. Criteria used in its diagnosis are diminution in size of the hemithorax, elevation of the diaphragm, shift of the neighbouring structures towards the affected area, and compensatory emphysema of the adjacent lung. All the foregoing signs may be absent if the collapse involves a small volume such as a bronchial segment. The following additional signs suggested by Robbins and Hale (1945) are then essential; displacement of visible septa, crowding of vascular shadows, and displacement of the hilar opacities. Oblique and lordotic views often usefully augment the information given by routine straight and lateral films. Tomography can also be of help. Bronchography is the most certain method, but each segmental bronchus must be identifiable and passed as normal before collapse can be eliminated. Unfortunately, from the point of view of determining the end-result bronchography was not performed as a routine in our cases; the acquisition of what was considered largely academic information did not justify, in our opinion, the administration of an anaesthetic in the younger child.

Consolidation.-Consolidation is a homogenous opacity approaching, at least, the size of a bronchial segment and showing no evidence of decrease in volume of the affected area of lung.

Collapse-CONSOlidation.-This was defined as a homogenous opacity in a segment or lobe which shows decrease in volume; there were two types.

Type 1.-Type 1 consisted of a homogenous opacity approaching, at least, the size of a segment and showing definite evidence of a decrease in volume, but of a lesser degree than in atelectasis.

Type 2.-Type 2 consisted of a collapsed or atelectatic area of lung containing a dense opacity of sufficient size to cause a very definite deformity of its outline.

The essential difference between type 1 and type 2 is in the degree of diminution of volume.

\section{MATERIAL}

Included in the series are all cases that showed consolidation and collapse-consolidation discharged from High Wood Hospital between January 1, 1949, and December 31, 1951; in all there are 86 cases.
There were three cases of collapse-consolidation type 2; on admission two of these showed large deposits of calcium in the collapsed area of lung and subsequent radiographs showed no change. The other resulted, after nine months, in small calcified foci in the collapsed segment. These three cases are not considered further.

Of the other 83 cases, radiographs from the date of first diagnosis were not available in all. Some cases classified as collapse-consolidation type 1 on admission to this hospital may have started as consolidation and in the interim period contracted. In view of this possibility it has been decided to group these two lesions together, particularly as no material difference in the various factors to be discussed was noted between them.

AGE AND SEX.-There were 43 boys and 40 girls, whose ages ranged from 2 months to 15 years.

TABLE I

AGE DISTRIBUTION

\begin{tabular}{c|l}
\hline Age (Years) & Number \\
\hline $0-1$ & $10(12 \%)$ \\
$1-2$ & $17(20 \%)$ \\
$2-5$ & $23(28 \%)$ \\
$5-10$ & $23(28 \%)$ \\
$10-15$ & $10(12 \%)$ \\
\hline
\end{tabular}

Sixty per cent. of cases occurred in children under the age of 5 years. Patients of this age group comprised only one-third of all cases of primary pulmonary tuberculosis admitted to this hospital during the period concerned. It appears that this type of lesion is more likely to occur in children under the age of 5 years in whom there is the greatest enlargement of bronchopulmonary glands in the course of the primary infection and the highest incidence of bronchial involvement (Richards, 1944b; MacPherson and Lutwyche, 1950).

INTERVAL BETWEen Tuberculin CONVERSion AND ONSET OF CONSOLIDATION

In 62 cases $(75 \%)$ consolidation or collapseconsolidation type 1 was present at the time of the first diagnosis of primary pulmonary tuberculosis; in eight of these erythema nodosum, which may be taken to herald the onset of tuberculin sensitivity, was the presenting symptom. All were radiographed at the time or very soon after the skin manifestation (Fig. 1a, 5a).

One child aged 2 months was found to have a consolidation of the left upper lobe excluding the lingula (Fig. 6a); the Mantoux test was positive. and the mother had pulmonary tuberculosis. 


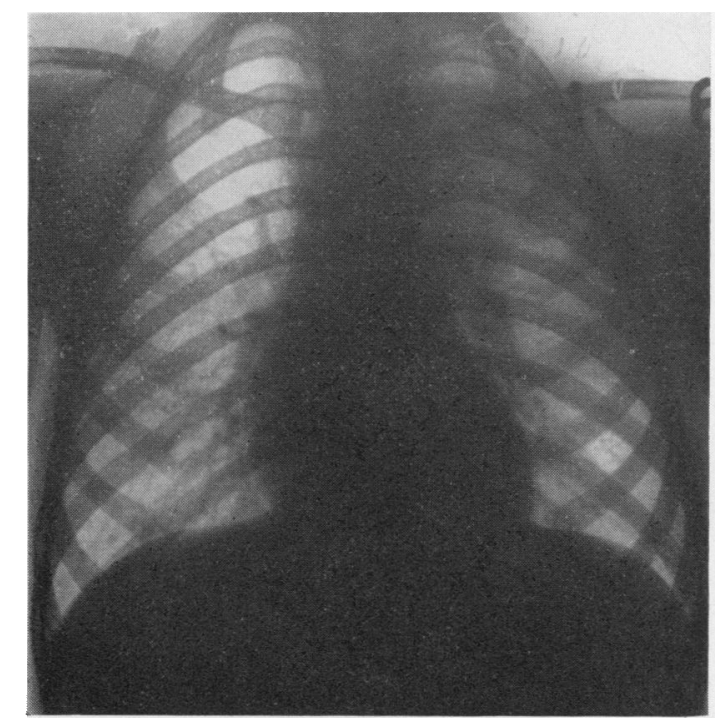

FIG. 1a.-A girl aged 5 years with erythema nodosum; consolidation posterior segment of left upper lobe.

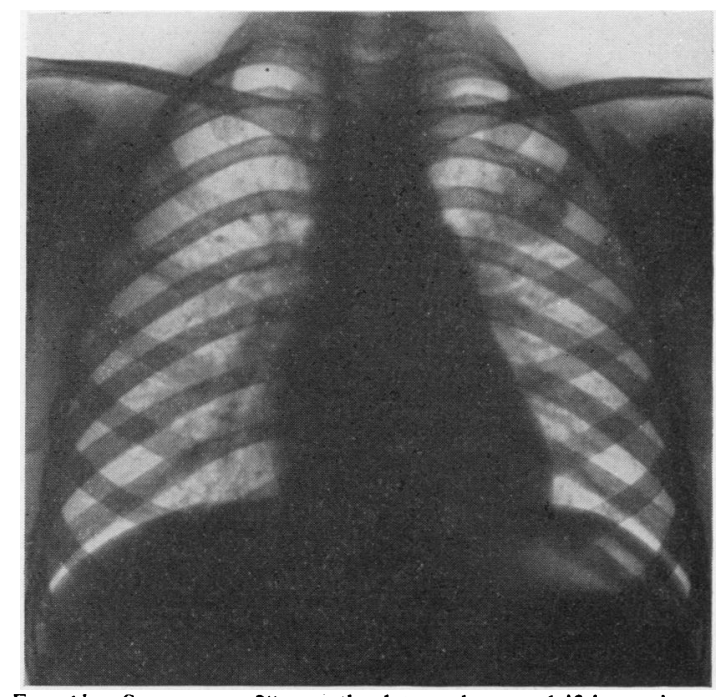

FIG. 1b.-Same case, 20 months later; large calcifying primary focus, no evidence of collapse.

In 17 cases $(20 \%)$ consolidation or collapseconsolidation type 1 did not appear until a varying interval after the first diagnosis of primary pulmonary tuberculosis (Case 1, Fig. 7a, b). In eight of these all the radiographs were available and the intervals were one month, two months, three months, four months (two cases), five months, eight months, and 14 months.

From the above it is apparent that consolidation or collapse-consolidation can occur at the time of Mantoux conversion or at any stage of the active primary complex.

\section{SignS AND SYMPTOMS}

SYMPTOMS.-Symptoms were often protean and non-specific, consisting of lassitude, headache, anorexia, and failure to gain weight. In seven cases $(9 \%)$ symptoms were absent throughout the whole course.

The onset was insidious or subacute in the majority. Occasionally there was an acute pyrexial onset, usually with cough; wheeziness, pain in the chest, and headache may be other associated symptoms. These were often diagnosed as lobar pneumonia or acute bronchitis, but failure to respond to sulphonamides or penicillin induced a revision of the diagnosis. The acute phase lasted between two and three weeks, after which the clinical picture might be normal, or, more commonly, chronic symptoms of cough and vague ill health persisted.

Cough was the commonest symptom, very occasionally accompanied by blood-stained sputum, and rarely with a history of having coughed up fragments of caseous material. A few cases presented with paroxysmal cough and were first diagnosed as pertussis; the persistence of cough and malaise induced further investigations.

Erythema nodosum, usually accompanied by pyrexia, was the only presenting symptom in eight cases.

The occasional case was investigated because of enlarged cervical glands or phlyctenular conjunctivitis.

The duration of symptoms was variable, cough, a below-par appetite, and malaise sometimes persisting up to six months, rarely for 12 months. Low grade pyrexia often continued for two to six months. The erythrocyte sedimentation rate not infrequently remained raised for six months and a weight curve was flat for the same period.

Signs.-Except in the case with an acute pyrexial onset, the patient does not appear as acutely ill as his radiograph would have led one to believe. The respiration rate is not affected, a point useful in differentiating the case of acute onset from lobar pneumonia which it may otherwise simulate closely.

Physical signs of consolidation are often absent unless a whole lobe is affected. Bronchial obstruction of one of the main bronchi may produce its characteristic expiratory wheeze, which is usually transient.

After resolution of the lesion there may be moist sounds suggestive of residual bronchiectasis.

\section{ANATOMICAL Distribution}

In 80 cases the lesions were of segmental or lobar distribution, in three non-segmental (Fig. 8a, $b$ ). 
The right lung was affected in 60 cases $(72 \%)$ and the left in $22(27 \%)$, and there was bilateral involvement in one.

TABLE II

ANATOMICAL DISTRIBUTION OF LESIONS

\begin{tabular}{|c|c|c|c|c|c|c|}
\hline \multicolumn{3}{|c|}{ Upper Lobe } & $\begin{array}{l}\text { Middie } \\
\text { Lobe }\end{array}$ & \multicolumn{3}{|c|}{ Lower Lobe } \\
\hline & $\mathrm{R}$. & L. & & & R. & L. \\
\hline $\begin{array}{l}\text { Whole lobe } \\
\text { exclud ing lingula }\end{array}$ & 6 & $\begin{array}{l}2 \\
4\end{array}$ & $\begin{array}{c}\text { Whole lobe, } \\
17\end{array}$ & $\begin{array}{l}\text { Whole lobe } \\
\text { All basals }\end{array}$ & $\begin{array}{l}3 \\
4\end{array}$ & $\begin{array}{l}0 \\
1\end{array}$ \\
\hline $\begin{array}{ll}\text { Anterior } & \ldots \\
\text { A pical } & \ldots\end{array}$ & $\begin{array}{r}18 \\
1\end{array}$ & $\begin{array}{l}1 \\
5\end{array}$ & $\begin{array}{l}\text { Lateral seg- } \\
\text { ment, } 3\end{array}$ & $\begin{array}{ll}\text { Apical } & \ldots \\
\text { Subapical } & \ldots\end{array}$ & $\begin{array}{l}7 \\
2\end{array}$ & $\begin{array}{l}1 \\
1\end{array}$ \\
\hline $\begin{array}{l}\text { Posterior } \\
\text { Lingula } \\
\text { Non-segmental }\end{array}$ & $\begin{array}{l}3 \\
1\end{array}$ & $\begin{array}{l}3 \\
3 \\
1\end{array}$ & & $\begin{array}{l}\text { Posterior basal } \\
\text { Anterior basal } \\
\text { Lateral basal. . } \\
\text { Cardiac . } \\
\text { Non-segmental } \\
\text { Not known ... }\end{array}$ & $\begin{array}{l}2 \\
4 \\
1 \\
2 \\
1 \\
0\end{array}$ & $\begin{array}{l}2 \\
0 \\
0 \\
0 \\
0 \\
1 *\end{array}$ \\
\hline Total, 100 & 29 & 19 & 20 & & 26 & 6 \\
\hline
\end{tabular}

* Left lower and middle zones, lateral films not available.

Including the single case of bilateral involvement, there were seven cases $(8 \%)$ in which more than one lobe was affected (Fig. $2 a, b$ ); in five cases there was involvement of more than one distinct segment of the same lobe.

In 80 cases 97 separate segments or lobes were affected, in three the lesions were non-segmental. The upper lobes were involved in 45 cases (right 28 , left 17), the right middle lobe in 20 , and the lower lobes in 27 (right 21, left six).

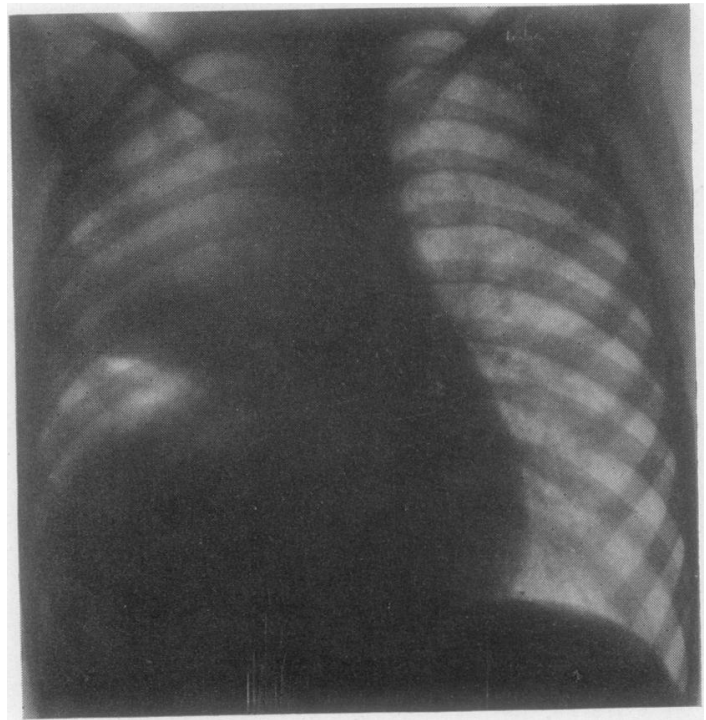

FIG. 2a.-A girl aged 4 years; consolidation involving the anterior segment of the right upper lobe, the anterior and posterior basic segments of the right lower lobe. First diagnosed pertussis, but symptoms persisted.

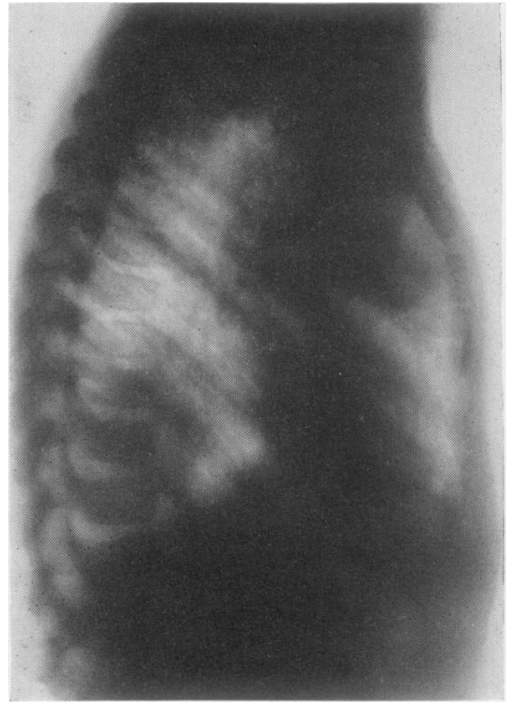

FIG. 2b.-Same, lateral film.

As single units the right middle lobe and the anterior segment of the right upper lobe were the most commonly affected.

\section{Radiological Course}

While the radiological course showed individual variations there was, nevertheless, a pattern with a tendency to slow resolution, leaving, in the majority of cases, residual segmental or lobar collapse.

During the first four to six months the opacity showed only slight changes or even remained static. A definite decrease in the size was noticed by six to nine months. Once marked clearing had occurred further changes were comparatively rapid. The whole process from the first diagnosis of the lesion to the end-result of collapse or atelectasis varied between nine and 15 months (Fig. $3 a$, $b, c, d)$. When the stage of collapse or atelectasis had been reached the only further changes were contraction, with re-aeration in the latter. The residual opacity is streaky and not always easily defined.

Exceptions are seen. The course may be delayed and a large opacity may still be present after 15 months. On the other hand, clearing may occur as early as three months. The tendency was for the course to be shorter in lower lobe lesions as compared with those in the upper lobes.

Not infrequently the first change is an increase in the opacity following which the radiological course is that described above. A "spreading" consolidation occasionally occurred, an area of consolidation progressively increasing until a whole 
lobe might become involved (Fig. $4 a, b, c, d, e$ ). These increasing opacities were usually associated with anorexia, general malaise, pyrexia, and a raised erythrocyte sedimentation rate.

While the end-result is almost invariably collapse or atelectasis of part or all of the originally affected area of the lung, a minority of cases completely resolved leaving no residuum except, possibly, a focus which may later calcify (Fig. $1 a, b$ ).

Occasionally the essential changes were progressive calcification beginning about nine to 12 months after the first diagnosis of the lesion; the end-result is scattered chunks of calcium throughout the original lesion which must have been essentially an area of caseation (Fig. $5 a, b$ ).

A few end in collapse-consolidation type 2 which is essentially a collapsed or atelectatic area of lung containing a space-occupying lesion which may or may not be calcified (Fig. 9a, $b$, Fig. 11).

\section{BRONCHOSCOPY FINDINGS}

Bronchoscopies were performed in 35 cases, more than once in six, numbering in all 45 . The youngest patient undergoing this investigation was aged 1 year 2 months, the oldest 14 years.

One case developed pyrexia and rapid respirations three days after operation; there was an immediate response to sulphonamides. No other complications were seen.

The interval between the date of the first diagnosis of the pulmonary lesion and bronchoscopy varied from three to 24 months, less than 12 months in 26 cases and more than 12 months in nine cases. Because of this long interval the pulmonary lesion had largely resolved at the time of bronchoscopy in some, and in others a possible bronchial lesion might have resolved.

Abnormal findings occurred in 28 cases (80\%), on the same side as the parenchymal lesion in 26 and on the contralateral side in two. No abnormality was seen in seven.

Bronchial Perforation.-Evidence that tuberculosis of a bronchopulmonary gland had invaded the bronchial lumen was afforded by the presence of granulations in 16, a probable past invasion by cicatricial stenosis or deformity in three. Thus, at the time of bronchoscopy in 19 cases $(57 \%)$ there was evidence of contemporary or past perforation.

External Pressure Deformity.-In five cases $(14 \%)$ bulges in the bronchial walls suggested pressure from large glands.

SuBMucous Lesions.-Large soft swellings producing considerable reduction in the bronchial lumen were seen in two cases. In one of these the finding was contralateral to a consolidated right middle lobe but before bronchoscopy there had been. a sudden massive atelectasis of the left lung (Fig. 10a) which had re-expanded in 36 hours; the sub-mucous lesion was found in the left main bronchus. This patient also had miliary tuberculosis.

Mucosal Ulcers.-Two shallow mucosal ulcers were seen in one case which also had granulations.

TUBERCLES.-A solitary mucosal tubercle was seen in one case. In the case of miliary tuberculosis with consolidation of the right middle lobe and sudden massive atelectasis of the left lung already referred to, several small tubercles were seen in the left main bronchus.

Pent-uP Pus.-In one case pus was released by punching out granulations.

Contralateral Lesions.-In two cases the bronchial lesion was situated on the opposite side of the bronchial tree to that of the lung containing the consolidation; one has already been referred to. In the other, a non-segmental lesion (Fig. $8 a, b$ ), the original consolidation in the right lung had resolved at the time of bronchoscopy leaving a residual calcified focus; there were also two calcified foci in the contralateral left lung (Fig. 8c). Granulations were found in the left main bronchus.

No ABNORMALITY.- - In seven cases, apart from a wide main carina, which has been almost universal in our cases of primary pulmonary tuberculosis that have come to bronchoscopy, no bronchial abnormality was discovered. The right middle lobe was affected in three, the right lower lobe in three (a single segment in two, all basal segments in one), and the left upper lobe excluding the lingula in one. In the last the left upper lobe bronchus was not visualized. It is possible that in some of these cases a bronchial lesion existed beyond the limited range of the bronchoscope, such as occurred in two of Fish and Pagel's cases (1938) in which a caseous focus had perforated into a bronchus. All seven cases were left with a collapse of all or part of the affected volume of lung.

DURATION OF ACTIVITY IN BRONCHOPULMONARY GLANDS.-Granulations were seen in bronchi as early as three months after the first diagnosis of the parenchymal lesion and as long as $\mathbf{2 4}$ months after. An external pressure deformity of a bronchus was found as late as $\mathbf{2 0}$ months after.

Histology.-Sections of the material removed at bronchoscopy showed tuberculous granulation tissue in various stages of necrosis. In 16 cases where bronchial secretions were aspirated these were 
positive for tubercle bacilli on smear in one, on smear and culture in two, on culture in two; negative on smear in two, and negative on culture in nine. In the 11 in which the bronchial secretions were negative for tubercle bacilli, granulations were present in six.

Because of the comparatively long interval between the onset of consolidation and bronchoscopy it was not possible to confirm or contradict a statement of Soulas and Mounier-Kuhn (1949) that a consolidation takes place before bronchial perforation occurs, and that if and when the latter takes place it has no effect on the course of the parenchymal lesion. However, the fact that, except for three cases, one in which a solitary tubercle was found and the two contralateral lesions, the bronchial lesion was in significant anatomical relationship to the consolidation suggests that the former is an aetiological factor in the development of the latter.

BronchosCOPIC AIMS AND INDICATIONS.-The aim of bronchoscopy was to confirm the presence, nature, and extent of a bronchial lesion and to improve and maintain an airway by repeated bronchoscopies if necessary; in one case pent-up pus was released. Obstructive emphysema was observed in four cases and was considered a definite indication. Granulations were punched out and fibrous stenoses were dilated with bougies.

RESULTS OF BRONCHOSCOPY.--In 34 cases bronchoscoped the lesions were of segmental or lobar distribution; 33 terminated in collapse or atelectasis and one in complete resolution. In this latter case no active measures were possible and bronchoscopy could not have influenced the end-result. As regards averting collapse in parts of the lung unaffected by a consolidation, none of the four cases with obstructive emphysema developed collapse in the zones affected by the latter.

Failure to prevent collapse in spite of bronchoscopy might have been due to various factors. The lateness in the course of the lesion at which bronchoscopy was performed possibly contributed to its ineffectiveness. The upper lobe segmental bronchi, with the exception of the lingula bronchus, are not accessible to bronchoscopic manipulation, nor, in our experience, is the right middle lobe amenable to this procedure, perhaps due to the massive arrangement of glands around its bronchus (Brock, 1950). Further, the lung tissue may no longer be capable of re-expansion.

\section{Fresh Consolidation}

In four cases a new area of consolidation (two cases) or collapse-consolidation type 1 (two cases) appeared at varying intervals (two, seven, nine, 19 months) after the first diagnosis of the original lesion. The new lesion was on the same side as the original in each case. Fig. $3 a$ shows collapseconsolidation type 1 of the right middle lobe; 19 months after the first diagnosis consolidation of the right lower lobe developed (Fig. 3e).

At the time of the appearance of the new opacity the original lesion had resolved with residual atelectasis in one, residual collapse in one (Fig. 3d), and no essential change in two. In one of the latter the primary focus was beginning to calcify.

The onset of the fresh consolidation was accompanied by an acute pyrexial illness in one case; two other patients had a cough and were losing weight; there were no symptoms in one and the lesion was found on routine radiography.

Three were bronchoscoped at intervals of three, four, and five months after the occurrence of the fresh lesion; intra-bronchial granulations were present in all.

These fresh consolidations followed the radiological course as already described, resolution taking place over a period of 10 months, nine months, eight months, and three months. Three terminated in collapse of the whole of the consolidated volume of lung (right lower lobe, one, Fig. $3 f$; right middle lobe, one; anterior and cardiac sectors of right lower lobe, one), and one in complete resolution with no residuum (right middle lobe).

The fact that these fresh lesions were of a segmental type and that they behaved as the majority of consolidations in this series suggests a similar pathogenesis.

\section{FIG. 3a.-A girl aged 3 years; a collapse-consolidation type 1 of the right middle lobe, enlarged paratracheal glands; first diagnosed consolidation of the right middle lobe nine months previously.}

FIG. $3 b .-$ Same, lateral film.

Fig. 3c.-Same case seven months after $3 a$. Partial resolution

FIG. 3d.-Same case two months after $3 a$. Collapse right middle lobe, radiological course 18 months

FIG. 3e.-Same case one month after 3d. Fresh consolidation involving the right lower lobe occurring 19 months after the first diagnosis. No response to 12-day course of penicillin and five-day course of sulphonamides. Bronchoscopy four months five-day course of sulphonamides. Bronchoscopy four months later showed
bronchus.

FIG. 3f.-Same case seven months later. Collapse of right middle and lower lobes. Note displaced septum minor 


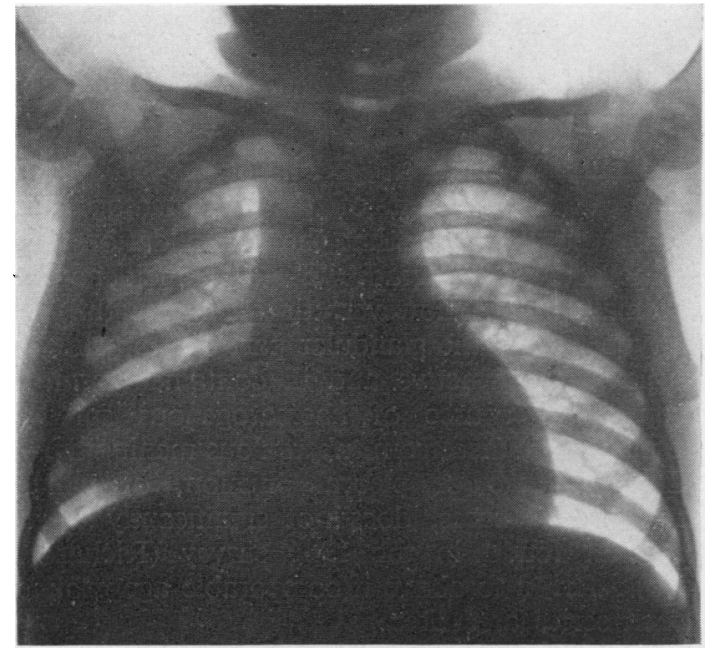

$3 a$

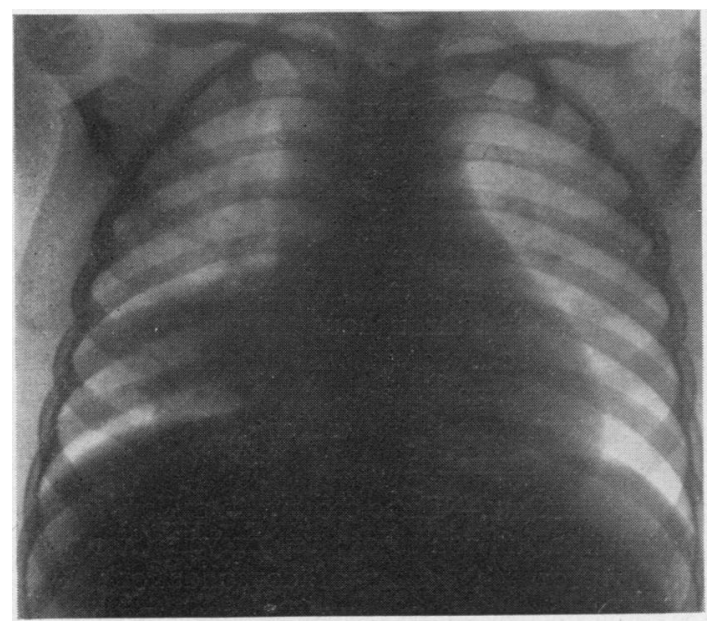

$3 c$

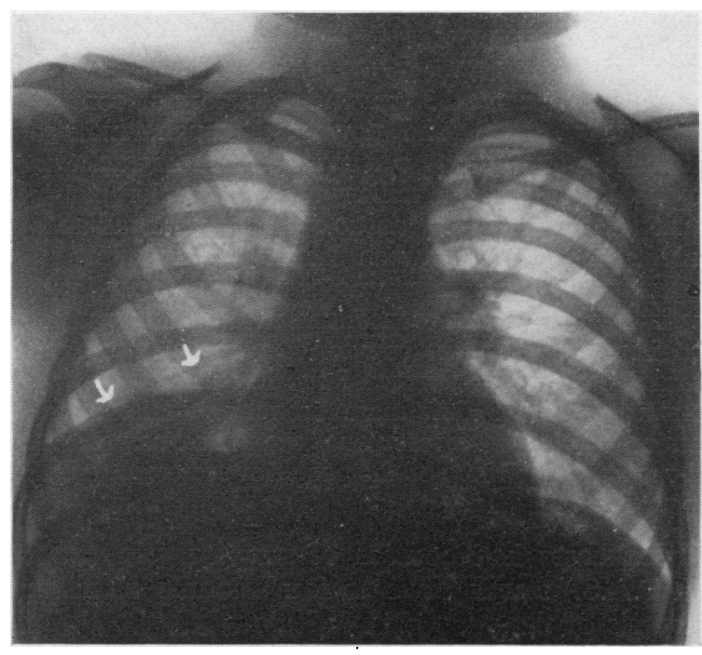

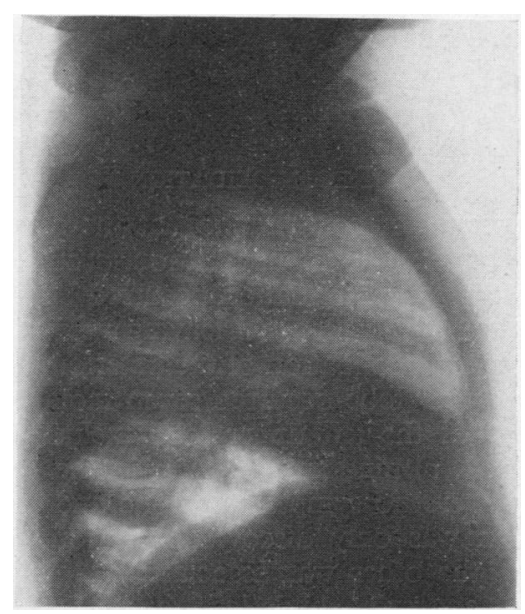

3b

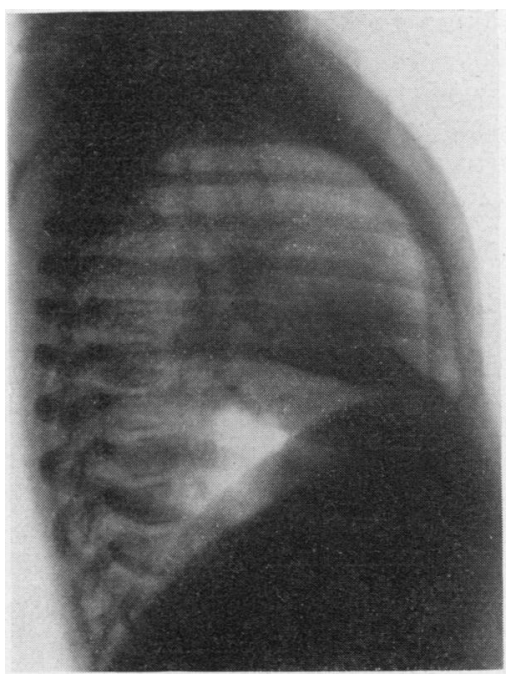

3d

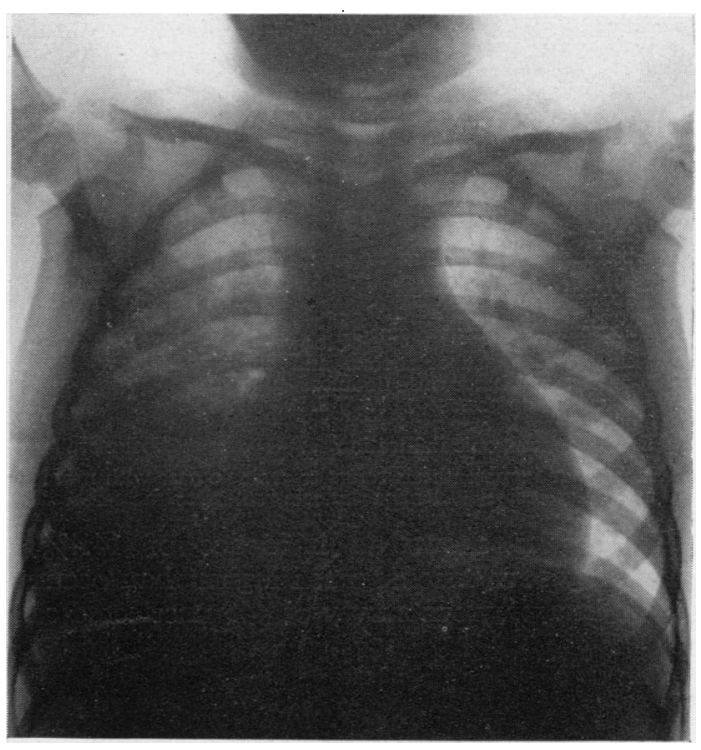

$3 e$ 


\section{RECONSOLIDATION}

Recurrence of consolidation at the same site as that of a previous consolidation occurred twice. By the time reconsolidation occurred both original lesions had largely resolved, leaving residual collapse in one. Reconsolidation of the anterior segment of the left upper lobe occurred seven months later in one, and of the left upper lobe excluding lingula (Fig. $6 a, b, c)$ nine months later in the other.

There were no symptoms in one and the reconsolidation was only discovered on routine radiography; the other was associated with low grade pyrexia, anorexia, and loss of weight. Bronchoscopy in one (left anterior segment lesion) revealed no abnormality.

Resolution took place in three months in one and in five months in the other, leaving in both residual collapse of the affected area of lung.

The pathogenesis of these reconsolidations is difficult to assess; in some it is probably the same as that of the original lesion, and in others secondary infection of a collapsed area of lung may be the cause. It is our view that both may occur, and each individual case will have to be judged on the merits of the radiological course, the clinical picture, and the response to penicillin or sulphonamides. In this connexion one of the above cases had a seven-day course of penicillin without response.

\section{Associated LesIONS}

Enlarged mediastinal glands were present in every case.

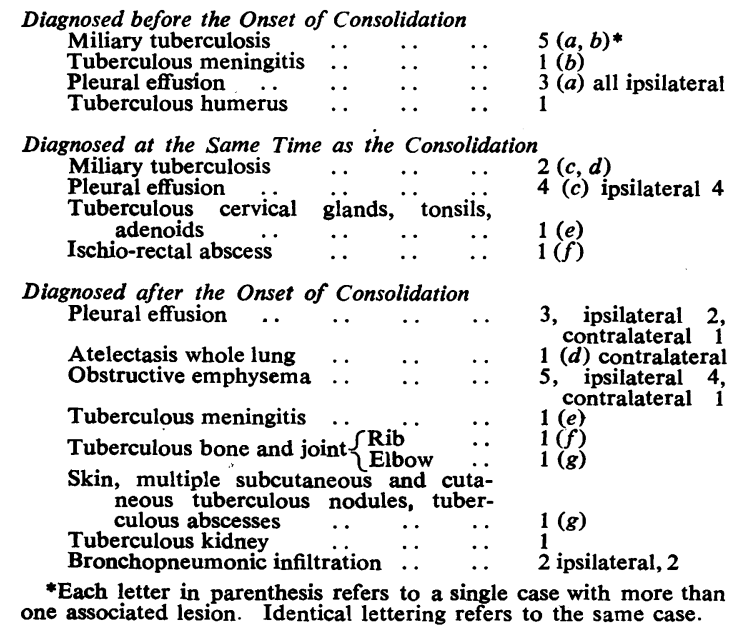

This series shows an incidence of $14.4 \%$ of haemotogenous lesions, much higher than occurred $(4.4 \%)$ in a previous survey of 445 unselected cases of primary tuberculosis (Richards, 1944b). The relative time of onset of these haematogenous lesions would suggest that the consolidation was not the source of spread. The high incidence of bronchial lesions, however, does suggest that in this type of case the glandular part of the primary complex is very active and ill contained, and is the probable source of haematogenous spread. One patient $(e)$ died from tuberculous meningitis.

The incidence of pleural effusion, of which there were 10 cases, does not significantly differ from that found in the 1944 survey (Richards, 1944b) referred to above if comparable age groups in each series are taken.

In spite of intrabronchial granulations and positive bronchial secretions, bronchogenic spread is, in our experience, uncommon and only occurred in two cases of this series.

\section{TREATMENT}

The basis of treatment was graduated rest as for tuberculosis in general; grading was based on the usual criteria. Rest in bed, before being allowed up one hour, was in the region of six to nine months, and the total stay in hospital was nine to 15 months. While in bed and throughout the whole period in hospital patients received full schooling.

On discharge patients were advised to lead a normal, unrestricted life unless there were any special contraindications.

CHemotheraPy.- Three cases with miliary tuberculosis had a full course of streptomycin (two with P.A.S.) before the onset of consolidation; two developed consolidation within one month of discontinuing chemotherapy, the other within two months. One bronchoscoped four months later showed abnormal findings recorded in the following case.

Case 1.-A girl aged 3 years had a history of contact. In February, 1949, she developed cough, malaise, irritability; symptoms persisted. A radiograph on March 20,1949, showed miliary tuberculosis, left pleural effusion, enlarged left aortic glands with adjacent opacity (Fig. 7a). Between March 25 and July 28 streptomycin, $0.5 \mathrm{~g}$. daily, was given. Radiographs on August 9 now showed consolidation of the left upper lobe (Fig. 7b). Bronchoscopy on December 17 revealed external pressure deformity of the left main bronchus, granulations in the left main bronchus. Histological examination showed tuberculous granulation tissue. The end-result was collapse of the posterior sector of the left upper lobe.

Seven cases had courses of streptomycin (three with P.A.S.) starting two to four months after the diagnosis of the parenchymal lesion; the length of 


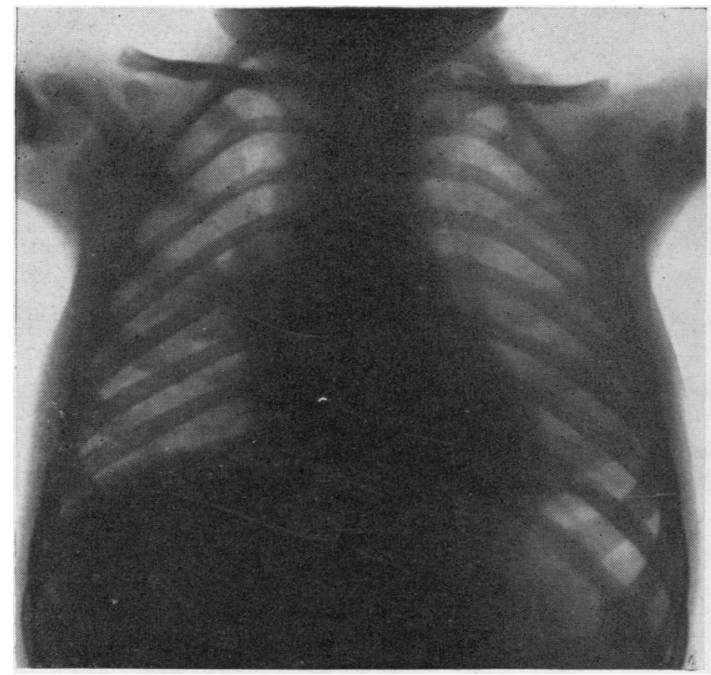

$4 a$

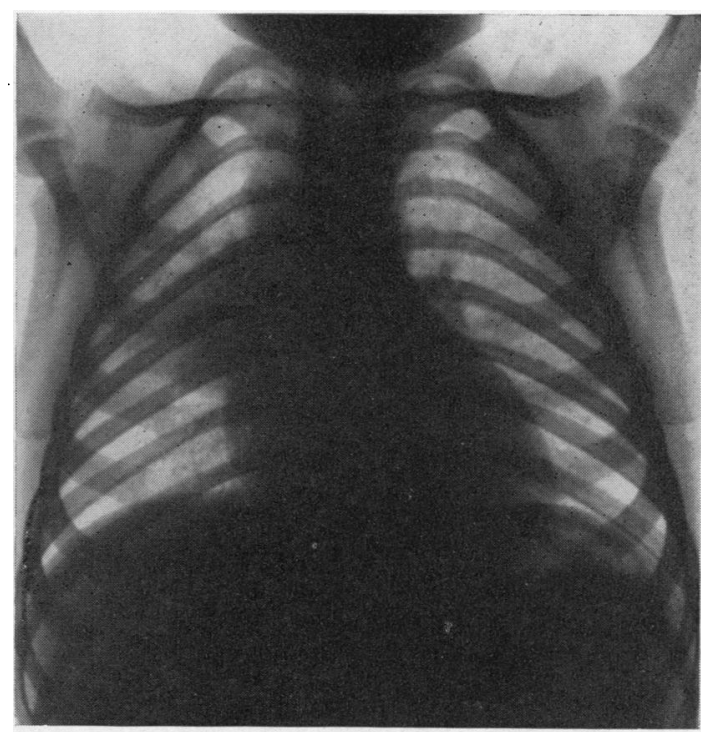

(5)

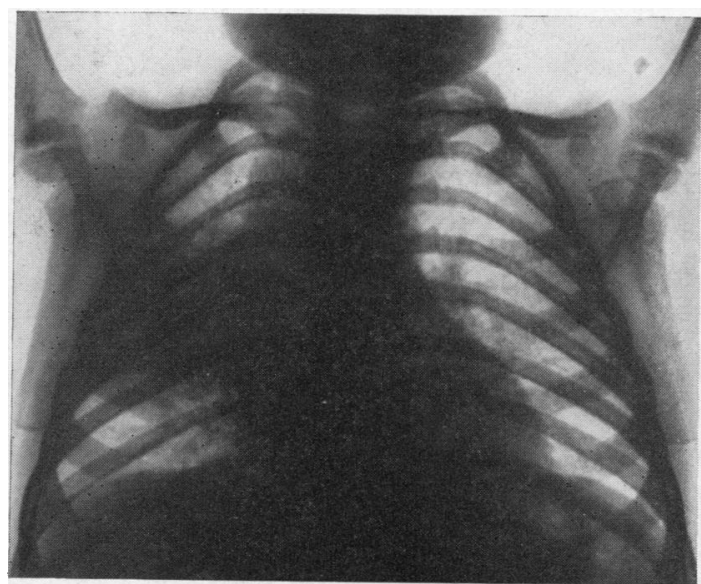

$4 c$

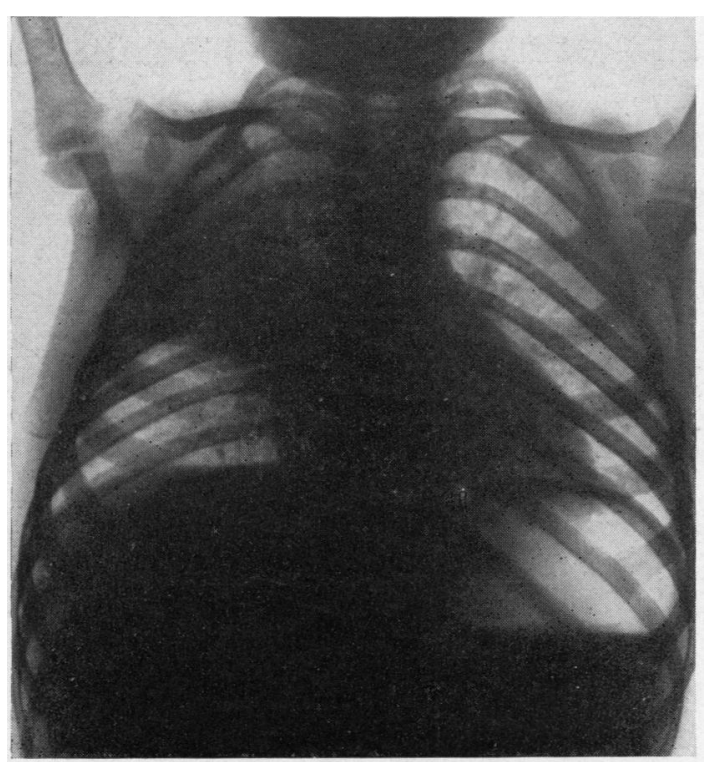

4b

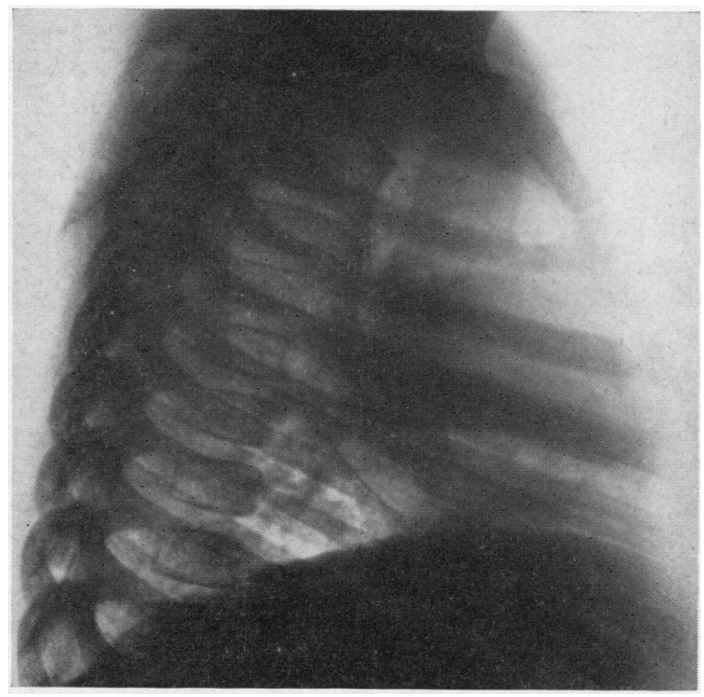

4d

Fig. 4.-" Spreading" consolidation in boy aged 2 years in spite of streptomycin and P.A.S.

FIG. 4a.-Right hilar adenitis with adjacent opacity.

Fig. $4 b$.-Same case six weeks after $4 a$. Increase in perihilar flare.

FIG. 4c.-Same case seven weeks after $4 b$. Consolidation of anterior segment of right upper lobe.

Fig. $4 d$.-Lateral film of $4 c$.

Fig. 4e.-Same case 12 weeks after $4 c$ and after three months course of streptomycin and P.A.S. Now consolidation of the whole of the right upper lobe. Bronchoscopy four months after this film showed polypoid mass of granulations in the right main bronchus, and mass of granulations in the right upper lobe bronchus. 
the course varied from two to six months. A month after beginning chemotherapy obstructive emphysema developed in one, and in another progressive spread of the consolidation continued throughout the three months' course of streptomycin and P.A.S. (Fig. 4).

Six cases were bronchoscoped, two towards the end of the course of chemotherapy and four at varying intervals of two to six months after completing the course. Granulations were present in three, external pressure deformity in one, submucous swelling and tubercles in the contralateral left upper lobe bronchus in one, and no abnormality in one.

Four cases ended in collapse, one in atelectasis, one in collapse-consolidation type 2 (Fig. 9b), and one in a minor degree of collapse.

Eight cases had long courses of P.A.S. starting one to four months after the diagnosis. Three were bronchoscoped and all showed granulations, one after a three-month course, one after a fourmonth course, and the other after a 10-month course. Five cases terminated in collapse (Fig. 3f'), one in resolution leaving a residual focus. Of two non-segmental lesions, the essential change in one was progressive calcification, and in the other resolution leaving a calcified focus (Fig. 8).

These cases are too few to draw any definite conclusions as to the value of chemotherapy in influencing or shortening the course of consolidation or collapse-consolidation, but they have demonstrated that streptomycin and P.A.S. do not prevent consolidation, do not reduce the size of mediastinal glands, or have any definite effect on intrabronchial granulations, nor do they prevent the occurrence of collapse or atelectasis. This result is not surprising, as not infrequently we have seen tuberculous cervical glands enlarge and break down in cases being treated with streptomycin and P.A.S. for miliary tuberculosis.

We feel that streptomycin and P.A.S. have no place in the treatment of primary pulmonary tuberculosis except in disseminate lesions, and used indiscriminately may mask the early symptoms of tuberculous meningitis. Also, as a prophylactic chemotherapy must be considered valueless; haematogenous lesions probably originate in most cases from mediastinal glands upon which streptomycin and P.A.S. are ineffective.

RESECTION.-Farly resection of the area of consolidation or collapse-consolidation is not, in our opinion, justified. The condition is comparatively benign and these lesions will in the majority of cases resolve. In a proportion a varying amount of calcium will be left, but in a small percentage the tuberculous process will progress behind a tight stenosis producing in effect a cold abscess of the lung with a radiograph of collapse-consolidation type 2 (Fig. 11). In this type of case resection is obviously desirable. Operative risks and technical difficulties will have to be carefully weighed against the chance of further contraction, resolution, and calcification. With a well-sealed lesion operation is seldom an emergency measure and a period of observation may safely be allowed before making a difficult decision.

EXCISION OF BRONCHO-PULMONARY LYMPH GLANDS.-Excision of lymph glands was not indicated in any case of this series. When the deformity of the bronchial tree produced by a very large tuberculous gland is so great that stridor is persistent, or recurs with every bout of crying, or with every respiratory infection, thoracotomy and removal is positively indicated. The intrabronchial rupture of a gland of this size is usually fatal; the volume and consistency of its contents make such an event a major hazard in which even prompt and repeated bronchoscopy is likely to be ineffective. If further experience of the operation proves to be a safe and effective procedure, indications for its employment may be extended.

\section{RADIOGRAPHS ON DISCHARGE}

The condition of individual lesions as judged by the final radiograph before discharge from hospital is given in Table 1II. Where more than one lesion existed in the same case the end-result might vary from area to area; for instance, one segment might terminate in collapse, and another in complete resolution.

TABLE III

FINAL RADIOLOGICAL FINDINGS IN 100 INDIVIDUAL

\begin{tabular}{|c|c|c|c|c|c|c|c|c|c|c|}
\hline \multicolumn{11}{|c|}{ LESIONS } \\
\hline & \multirow[t]{2}{*}{ No. } & \multirow{2}{*}{ 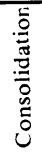 } & \multicolumn{2}{|c|}{$\begin{array}{c}\text { Collapse } \\
\text { Consoli- } \\
\text { dation }\end{array}$} & \multirow{2}{*}{ 商 } & \multirow{2}{*}{ 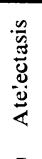 } & \multirow{2}{*}{ 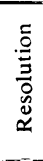 } & \multirow{2}{*}{ 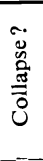 } & \multirow{2}{*}{ 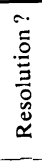 } & \multirow{2}{*}{ 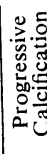 } \\
\hline & & & Type & Typ & & & & & & \\
\hline R. & $\begin{array}{l}75 \\
25\end{array}$ & $\begin{array}{l}2 \\
1\end{array}$ & $\begin{array}{l}8 \\
0\end{array}$ & $\begin{array}{l}4 \\
0\end{array}$ & $\begin{array}{l}42 \\
10\end{array}$ & $\begin{array}{l}7 \\
2\end{array}$ & $\begin{array}{l}6 \\
5\end{array}$ & $\begin{array}{l}3 \\
2\end{array}$ & $\begin{array}{l}1 \\
3\end{array}$ & $\begin{array}{l}2 \\
2\end{array}$ \\
\hline & 00 & 3 & 8 & 4 & 52 & 9 & 11 & 5 & 4 & 4 \\
\hline
\end{tabular}

Consolidation UnResolved (11 lesions).-One patient was discharged against advice after one month in hospital.

Two cases showed only partial resolution after periods of five and 15 months.

Eight patients after periods of observation of seven to 15 months still showed collapse-consolida- $\frac{?}{\mathbb{Q}}$ tion type 1 . 


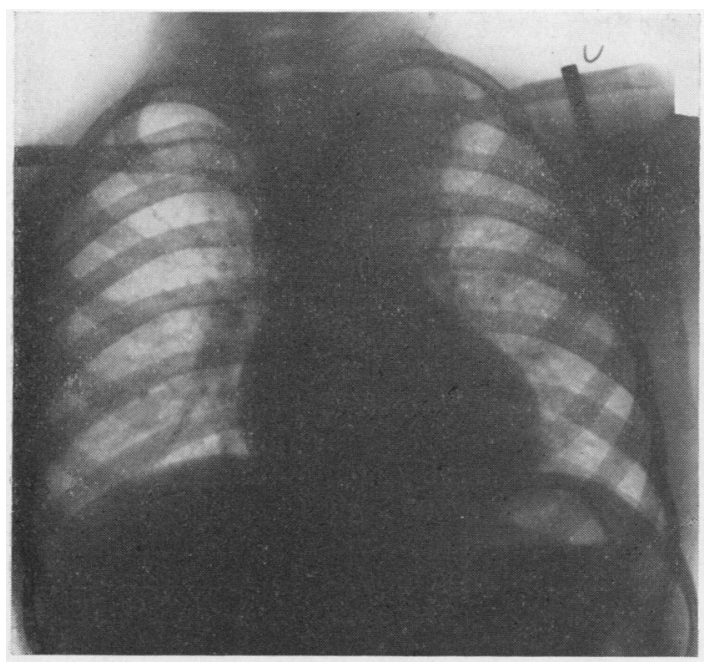

$5 \mathbf{a}$

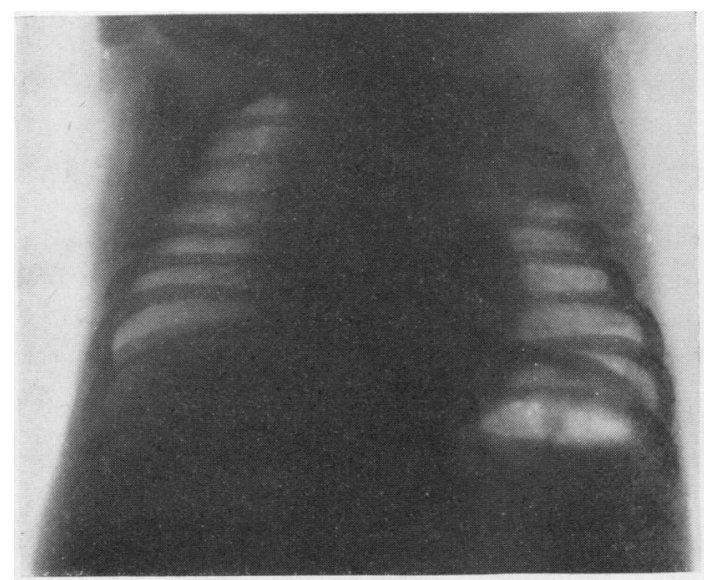

$6 \mathbf{a}$

FIG. $6 a$-Boy aged 2 months. Consolidation left upper lobe excluding lingula.

Fig. $6 b$.-Same case three months after $6 a$. Marked resolution.

FIG. $6 c$.-Same case nine months after $6 b$. Reconsolidation.

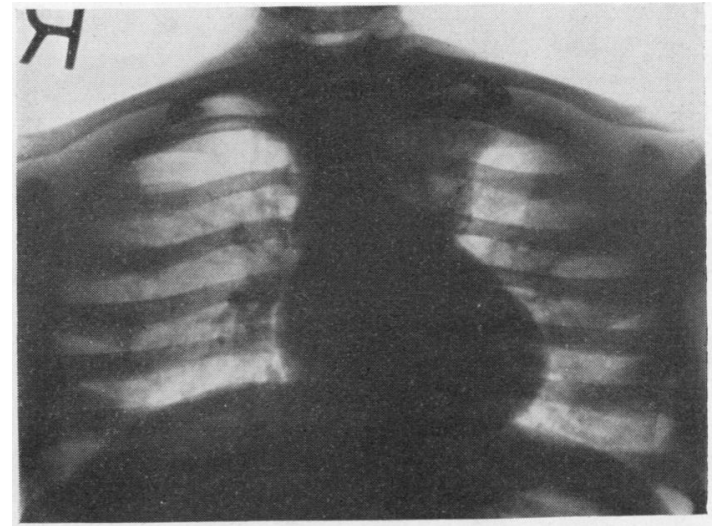

$\mathbf{5 b}$

Fig. 5a.-Girl aged 7 years with erythema nodosum. Consolidation apical sector of left upper lobe.

FIG. $5 b$-Same case 16 months later. Calcified masses throughout lesion. Original lesion must have been essentially of a caseating nature.

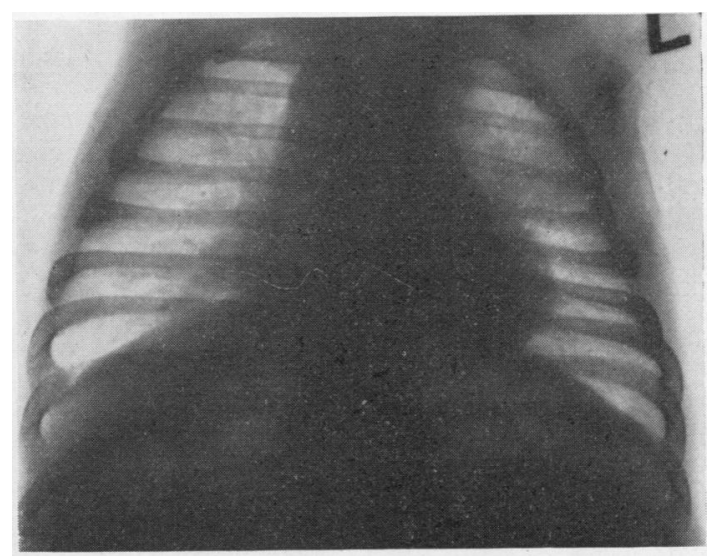

$6 \mathbf{b}$

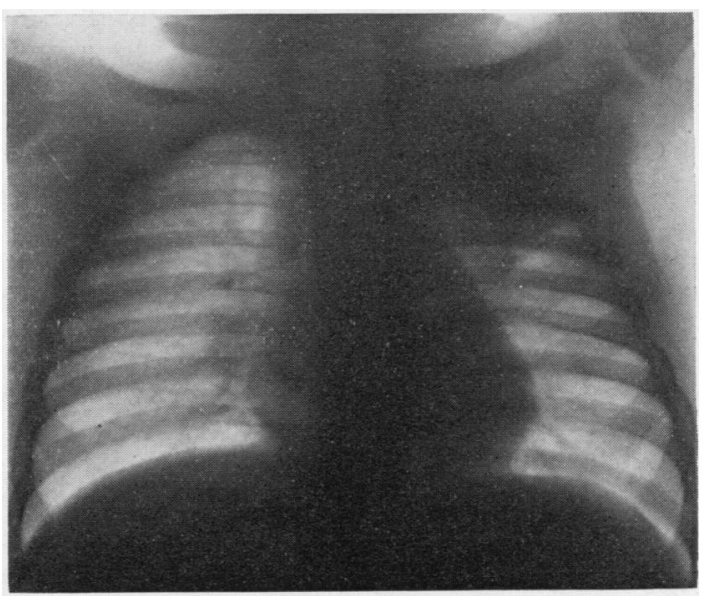

6c 
INDEFINITE FINAL Findings (nine lesions).-In nine cases, in the absence of bronchography, the final radiograph could not be read with certainty; five were thought to have terminated in collapse, but no definite decision could be made, similarly with four considered to have resolved.

Definite Final Findings (80 lesions).-Of the three non-segmental lesions two resulted in resolution leaving a small residual focus (Figs. $8 a, b, c$ ); the essential change in the other was progressive calcification.

In the remaining 77 lesions which were of segmental or lobar distribution the final findings were reasonably certain, and are shown in Table IV.

TABLE IV

FINAL $X$-RAY FINDINGS IN 77 INDIVIDUAL SEGMENTAL LESIONS

\begin{tabular}{c|c|c|c|c|c}
\hline Collapse & Atelectasis & $\begin{array}{c}\text { Collapse } \\
\text { Consoli- } \\
\text { dation, } \\
\text { Type 2 }\end{array}$ & Resolution & $\begin{array}{c}\text { Calcifica- } \\
\text { tion }\end{array}$ & Total \\
\hline 52 & 9 & 4 & 9 & 3 & 77 \\
\hline
\end{tabular}

Nine $(12 \%)$ lesions terminated in complete resolution leaving a residual focus in three (Fig. 1), and no residuum in six.

In three $(4 \%)$ lesions the essential change was progressive calcification (Fig. $5 a, b$ ), evidence of past caseation.

Four lesions ended in collapse-consolidation type 2 ; in two of these the collapsed area of lung contained sizeable areas of calcification as evidence of previous caseation (Fig. 9b, Fig. 11).

Fifty-two terminated in collapse, in 49 of all and in three of part of the originally affected area of lung.

Nine ended in atelectasis, in eight of all and in one of part of the originally affected area of lung.

Of 77 segmental or lobar lesions it is seen that $65(84 \%)$ terminated in collapse, atelectasis, or collapse-consolidation type 2 of all (in 61) or part (in four) of the originally affected area of lung.

Of 28 in which a whole lobe was originally affected, one (right middle) remained unresolved at the time of discharge, complete resolution occurred in two (right middle, two), a minor degree of collapse in one (right upper lobe), collapse of the posterior segment in one (left upper lobe), and the remaining 23 terminated in collapse, atelectasis or collapse-consolidation type 2 of the whole lobe (Fig. 3f, Fig. 9b, Fig. 11).

Of the total number of 83 cases three were of the non-segmental type, seven had not resolved at the time of discharge, and in seven the end-result was indefinite; of the remaining 66 cases (repre- senting 77 individual lesions) collapse, atelectasis, or collapse-consolidation type 2 of at least one segment occurred in $57(86 \%)$, complete resolution in six $(9 \%)$ and progressive calcification in three $(5 \%)$.

There is no doubt that in a given case of consolidation or collapse-consolidation type 1 the most likely end-result is collapse or atelectasis.

Re-expansion, if it is going to occur, does so early, within nine months. According to Macpherson and Lutwyche (1950), who reported reexpansion in 28 out of 32 cases, it may occur even after an interval of 10 years, but this finding can be criticized on the grounds that bronchography was only carried out in a few, and without this procedure the radiological diagnosis of collapse, particularly after a long period, can be extremely difficult. In a long follow-up Bentley and Grzybowski (personal communication) selected the anterior segment of the upper loke which is the easiest to interpret with reasonable certainty even after a long period; of 29 followed from 0 to two years, re-expansion only occurred in one; 14 were followed from three to 10 years, and collapse persisted in all. We, personally, have observed 103 cases of collapse or atelectasis due to primary pulmonary tuberculosis which were discharged from this hospital in the three years 1949-51 inclusive; the results are shown in Table V, where it is seen that re-expansion in these cases was uncommon.

TABLE $\mathrm{V}$

RESULTS OBSERVED IN 103 CASES OF COLLAPSE OR ATELECTASIS

\begin{tabular}{|c|c|c|c|c|}
\hline \multicolumn{3}{|c|}{$\begin{array}{l}\text { Period of } \\
\text { Observation }\end{array}$} & $\begin{array}{l}\text { Number } \\
\text { of Cases }\end{array}$ & $\begin{array}{c}\text { Number } \\
\text { Re-expanded }\end{array}$ \\
\hline $\begin{array}{l}\text { 0-6 months } \\
6-12 \quad, \\
12-18 \quad, \\
18-24 \quad ", \\
24-36 \quad,\end{array}$ & $\begin{array}{l}\ldots \\
\cdots \\
\ldots \\
\ldots\end{array}$ & $\begin{array}{l}\cdots \\
\cdots \\
\cdots \\
\ldots\end{array}$ & $\begin{array}{r}42 \\
39 \\
17 \\
2 \\
3\end{array}$ & $\begin{array}{l}5 \\
0 \\
2 \\
0 \\
0\end{array}$ \\
\hline
\end{tabular}

The period of observation was under 18 months in the majority, and bronchography was carried out in only 17 cases. The latter investigation confirmed the persistence of collapse in all 17, and it is our view that once collapse has occurred re-expansion is the exception. Histological examination of consolidations resected at Sully Hospital have shown almost complete disappearance of elastic tissue (Seal, 1952, personal communication), and the likelihood of re-expansion when the collapse is of a previous consolidation appears remote.

\section{COMPLications}

Excluding those cases which show large areas of calcification as evidence of previous caseation, the complications are of a non-tuberculous character. 


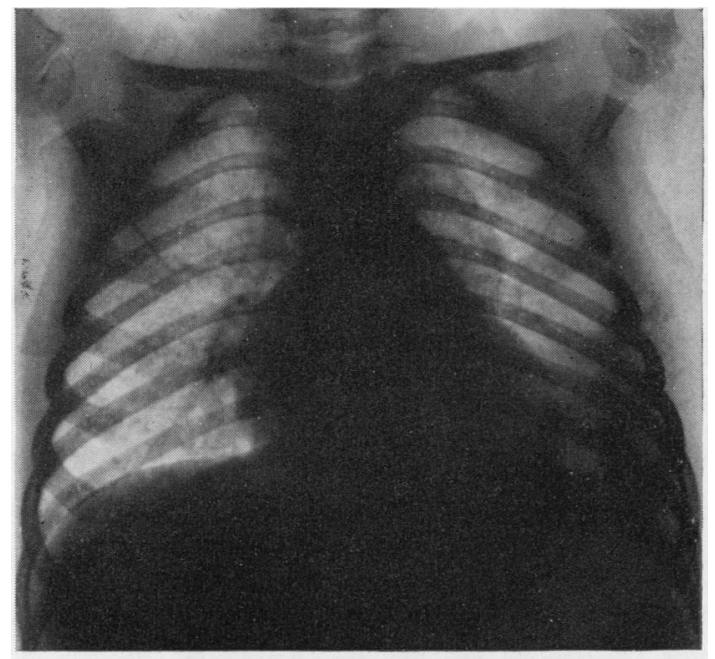

$7 \mathbf{a}$

Fig. $7 a$.-Girl aged 3 years. Miliary tuberculosis, left pleural effusion, perihilar opacity on left.

Fig. 7b.-Same case three and a half months later and 10 days after completing course of streptomycin; consolidation of left upper lobe. Bronchoscopy four months later showed granulations in left main bronchus.

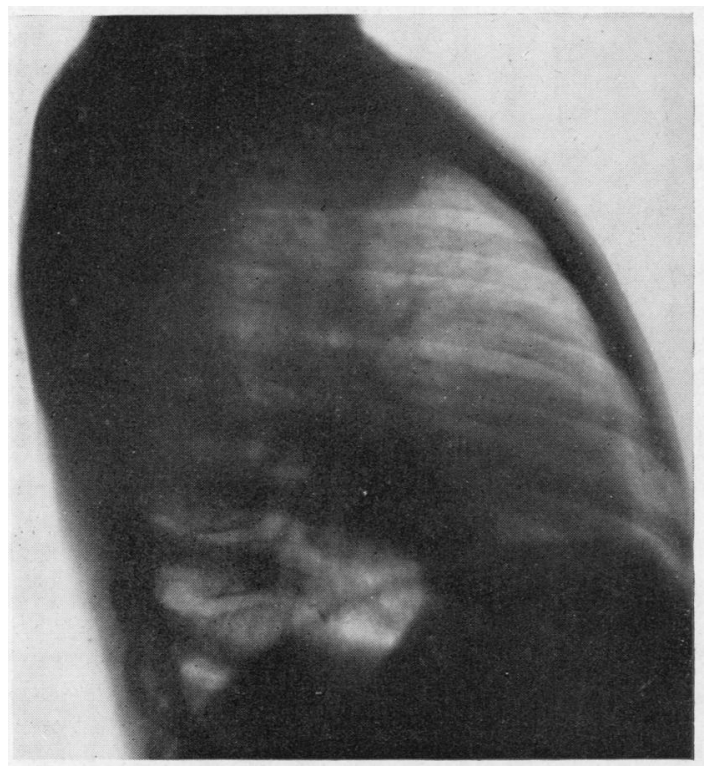

8b

Fig. $8 a$.-Girl aged 8 years. Non-segmental consolidation in right lower lobe, large focus left apex and another in left fourth space. Bilateral enlargement of hilar glands.

Fig. 8b.-Lateral film of $8 a$.

Fig. 8c.-Same case 16 months later. Calcified deposits right fifth space, behind first left costal cartilage, and in left fourth space. Calcified glands right root and upper left root. Granulations still present in lower part of left main bronchus.

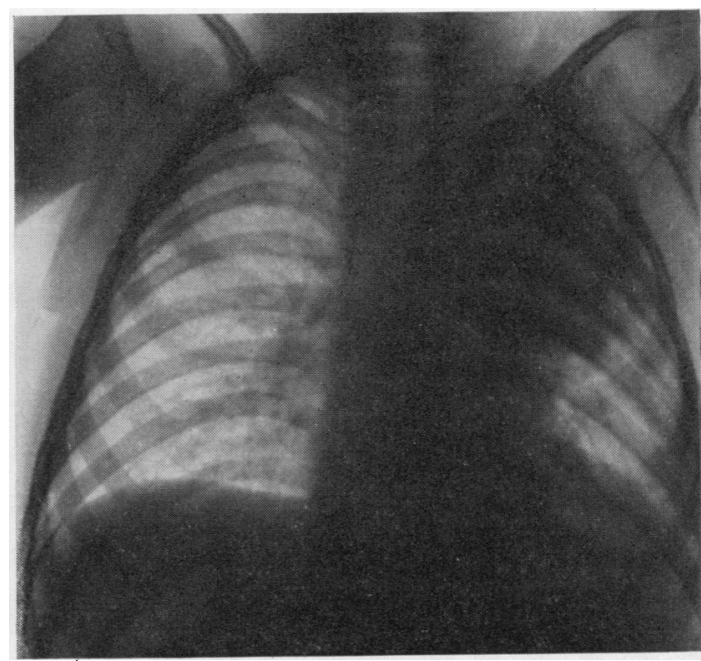

$\mathbf{7 b}$

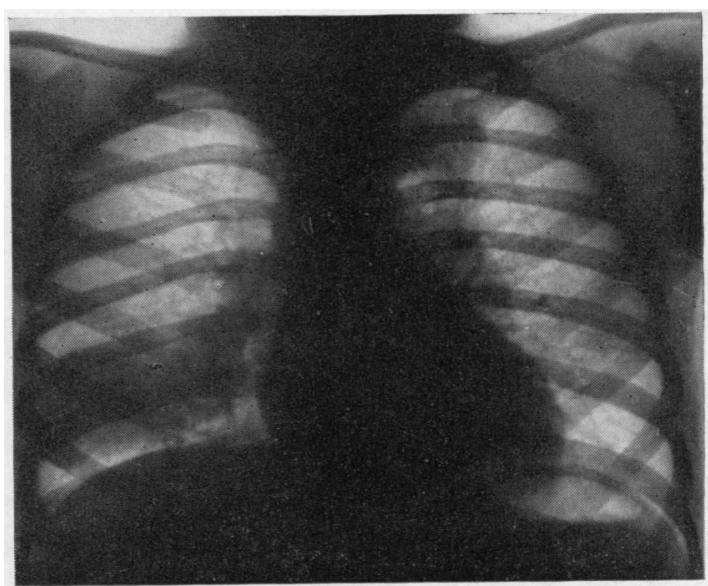

$8 \mathbf{a}$

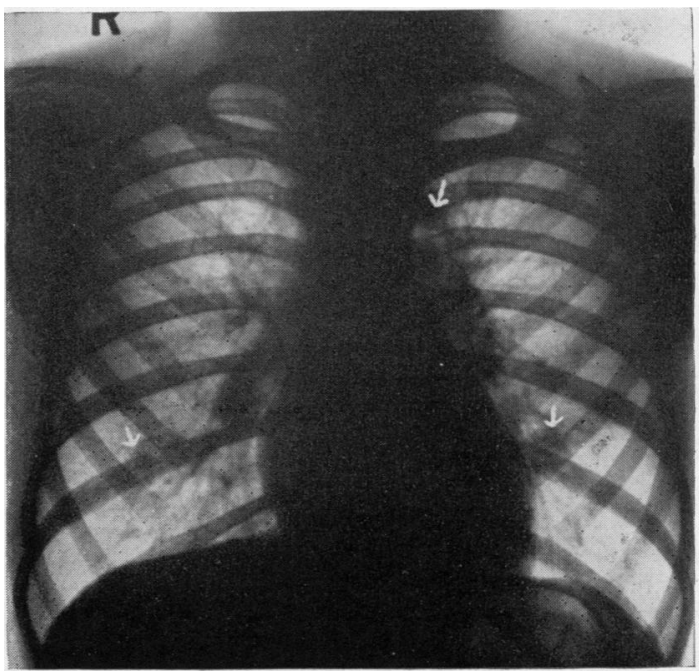

$8 c$ 
EARLY SeCONDARY INFECTION.-Acute secondary infection is a comparatively rare complication during the active phase of primary pulmonary tuberculosis; it occurred only once in this series. Up to the present we have always been successful in establishing drainage at bronchoscopy in this type of case, and maintained it by repeated bronchoscopies if necessary, and postural treatment subsequently. With the aid of antibiotics the acute infection has been overcome, and the question of resection considered months or years later when the tuberculous condition is approaching quiescence and the patient plump and fit. The one case in this series with pent-up pus later developed symptoms and the right middle and lower lobes were resected six years later.

CollaPSE AND BronChIECTASIS.-Eighty-six per cent. of cases in which the end-result was definite were left with collapse of at least one segment. These collapsed segments or lobes which are the result of a bronchial lesion in these cases do not, in our opinion, justify resection as a prophylactic measure. Bronchography in a proportion will reveal minimal cylindrical dilatations, and in others gross saccular bronchiectasis. Whatever the results of bronchography these collapsed segments are compatible with a normal, healthy life (Martin and Berridge, 1942) and resection should only be contemplated if and when symptoms or disability develop.

Bronchography was carried out in 10 cases in which bronchiectasis was highly suspected; the presence of collapse or atelectasis was confirmed in all. In one, the collapsed anterior segment of the right upper lobe failed to fill; a collapsed right middle lobe showed no evidence of bronchiectasis, and a blocked lateral bronchus of the right middle lobe was seen in another. Bronchiectasis was found in seven cases, slight cylindrical dilatations in one (left posterior basic segment), and saccular bronchiectasis in six (right upper lobe, one, anterior segment of the right upper lobe, one, right middle lobe, two, superior branch of the lingula, one, posterior segment of the left upper lobe, one; in the last filling of the other branches was incomplete).

Apart from the above, 10 other cases were suspected of bronchiectasis on radiological appearances or on the presence of moist sounds over a collapsed area of lung. One of these was readmitted a few months later as " reactivation of tuberculosis," and found to have cylindrical and fusiform bronchiectasis of the right middle lobe (Fig. 10b). One other developed symptoms and required resection of the right middle and lower lobes three years after discharge and six years after the active primary infection.

Of these 20 cases only one was definitely associated with secondary infection during the course of the active primary infection when pent-up pus was released at bronchoscopy; this was the case which later required resection. At the time of discharge all were symptomless and resection was not advised. It was deemed reasonable to postpone the question of surgery until the indications became more definite.

LATE Secondary Infection.-Acute or chronic infection of the collapsed segment or lobe may occur at varying intervals after the primary infection, even after 40 years as described by Brock (1950) in his account of the post-tuberculous middle lobe syndrome. When occurring comparatively early, within a few months or years after the primary infection, differentiation from re-activation of the tuberculous process should not be difficult, although, not infrequently, patients have been re-admitted to this hospital with a diagnosis of reactivation. A therapeutic trial of penicillin or sulphonamides will determine the diagnosis and confusion should not arise.

\section{Discussion}

Pathogenesis.-A visit to Sully Hospital at the invitation of Mr. Dillwyn Thomas and an inspection of his resection specimens of the type of case under discussion confirmed the account already given of the pathology of consolidations occurring in primary pulmonary tuberculosis. The radiographs of the Sully cases taken before operation were similar to those in our cases. If consolidation can be diagnosed on radiographic appearances and differentiated from atelectasis, as we maintain it can, it appears that a resolvable form does occur during the primary infection.

Although bronchoscopy was performed comparatively late in this series, the incidence of bronchial perforations and their anatomical relationship to the consolidated lung strongly suggest that the former lesion is an important aetiological factor in the majority of these cases.

Bronchial obstruction is a common complication of the primary tuberculous infection, and rerforation of a tuberculous gland into the lumen of a bronchus takes place in the majority of cases which show radiological evidence of obstruction. Atelectasis and collapse are common sequelae of the bronchial lesion. The aspiration of caseous material from the perforation may add an additional factor to the mechanical effect of obstruction. 


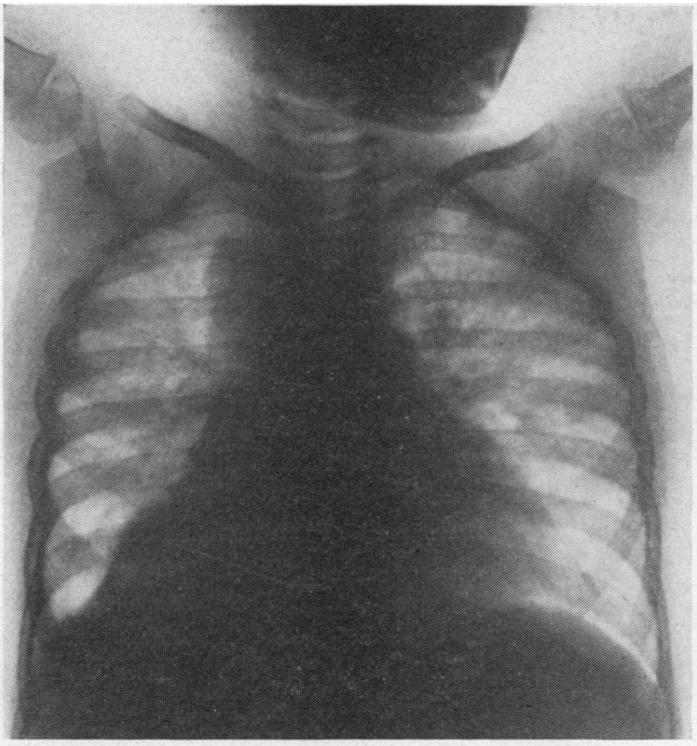

$9 a$

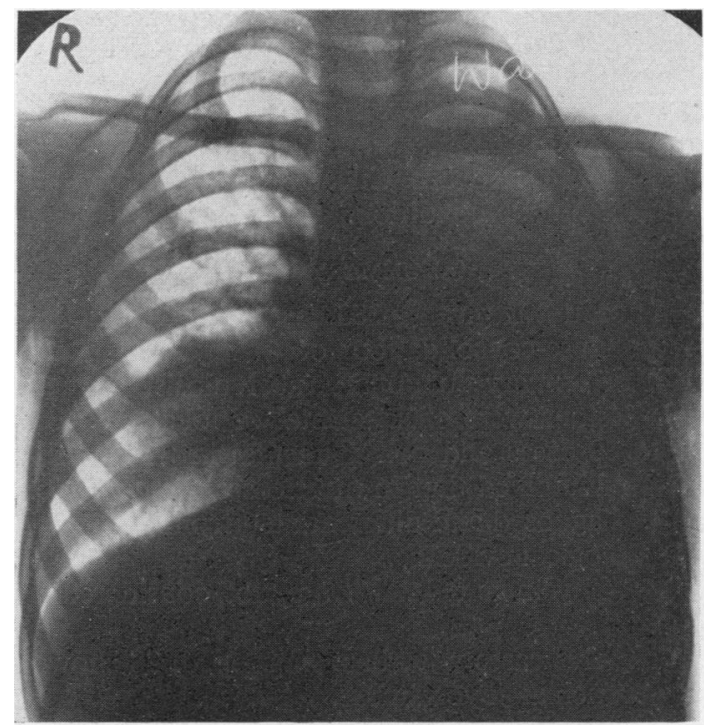

$10 \mathrm{a}$

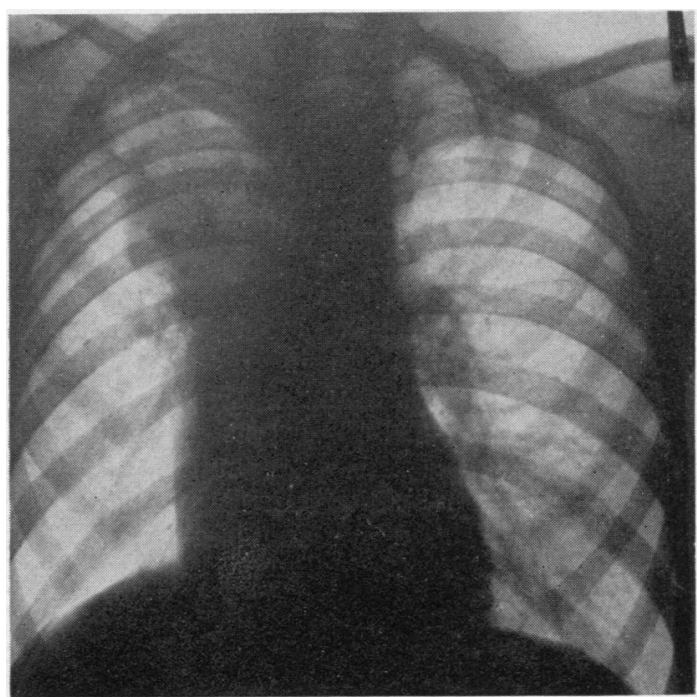


The aspirated material will contain tuberculoproteins and a variable number of tubercle bacilli, most of which will not be viable. As postulated by Rich (1944) the result of aspiration will depend on the numbers, viability, and virulence of bacilli in the material, and the degree of allergy in the individual. The result will be a consolidation which, in most cases, is resolvable, but in the occasional case considerable areas of caseation may occur. In this series the majority of consolidations did resolve, and only six cases were left with an area of calcification of any magnitude as evidence of previous caseation. Bronchoscopy findings have shown that the broncho-pulmonary glands may remain active for as long as 20 months, which will account for the development of consolidation, fresh consolidation, and reconsolidation many months after tuberculin conversion.

The pathogenesis of bronchial obstruction and aspiration of glandular contents will account for the origin of atelectasis, consolidation, and collapseconsolidation, conditions which we maintain can be differentiated on radiological evidence. The fact that the majority of cases in this series were left with an area of collapse or atelectasis implies that a significant bronchial obstruction is almost always present. It is arguable that the residual collapse is a result of contracture of the pulmonary lesion healing by fibrosis, but the radiographic appearances suggest segmental collapse resulting from bronchial occlusion, rather than the more irregular-shaped scarring of a local fibrotic lesion. In the few cases in which there was no resultant collapse it appears that bronchial perforation did not produce a major obstruction, or possibly inoculation of the lung was by another route.

Whether bronchial perforation can take place as early as the date of Mantoux conversion we have not had the chance of verifying. Several of our cases had consolidation at, or very soon after, conversion as evidenced by the appearance of erythema nodosum. According to Wallgren and Miller (1939) the primary pulmonary complex is not demonstrable before the onset of tuberculin sensitivity, and if this be the case bronchial perforation by the glandular component of the complex appears unlikely before the latter event. Wallgren and Miller quote Ligner (1931) as originally demonstrating the presence of tubercle bacilli in the gastric washings of infected children before the onset of tuberculin sensitivity, and a preliminary inoculation of the lung is possible during this period. With the onset of the second factor, allergy, the stage is set for the subsequent development of consolidation, the tuberculo-pro- teins arising from the preliminary inoculation and not from the perforation of glandular contents into a bronchus.

RESECTION.-Early resection is not justified. This series has shown that in the majority of cases the consolidation resolved, and even when caseation, as evidenced by subsequent calcification, was present the condition appeared to be benign. Some of the Sully resection material did correspond to our collapse-consolidation type 2 , and showed large areas of caseation. However, in our series this type went on to extensive calcification in the collapsed lobe (Figs. 9 and 11). Radiographs taken early in the course will not define the underlying pathology, and early resection will only subject many patients with a benign condition to unnecessary operation. Only a long follow-up will determine whether these cases with extensive calcification later break down with adult type tuberculosis. In our experience cases coming to resection within six years after the primary infection do so for infected bronchiectasis and not because of a tuberculous condition.

\section{SUMMARY}

An account is given of 83 cases of consolidation and collapse-consolidation occurring during the course of primary pulmonary tuberculosis.

The lesions were of segmental or lobar distribution in 80 cases and non-segmental in three cases.

It is maintained that in most cases the condition can be diagnosed and differentiated from atelectasis on radiological evidence.

Streptomycin and P.A.S. are not considered of value.

Thirty-five cases were bronchoscoped, 28 showed endo-bronchial involvement.

The consolidation is resolvable in the majority, and only six cases showed large areas of calcification as evidence of previous caseation.

Early resection is not justified.

In 66 cases in which the lesions were of segmental or lobar distribution, the final radiographs could be read with reasonable certainty. Fifty-seven $(86 \%)$ of these were left with residual collapse, atelectasis or collapse-consolidation type 2 , of at least one segment.

The view is expressed that re-expansion of the collapsed area of lung is uncommon. Bronchiectasis was definite in nine cases and suspected in 10 others. Resection is not advised unless symptoms arise.

The pathogenesis has been discussed and support is given to the views of previous authors that the condition is caused by the inoculation of tuberculous material in the lung of an allergic individual. 
The source of the inoculation is most probably, in the majority of cases, from a tuberculous bronchopulmonary gland which has perforated the bronchial wall.

We wish to thank Mr. Dillwyn Thomas for an invitation to visit Sully Hospital and inspect the resection material, and also Dr. J. Jacobs, Dr. R. Seal, and Dr. L. R. West of the same hospital for demonstrating and discussing the material. We are grateful to Dr. Brieger for translations of the German literature, and to Dr. Grzybowski for most helpful criticism. We should also like to acknowledge the clerical assistance given by Mr. A. E. Cole and Miss J. Tomkinson.

\section{REFERENCES}

Armand-Delille, P. F., and Lestocquoy, C. (1931). Rev. franç. Pédiat., 7, 683

Bateman, G. H. (1937). St. Thom. Hosp. Gaz., 36, 148.

Bentley, F., and Grzybowski, S. (1952). Personal communication. Brock, R. C. (1950). Thorax, 5, 5 .

Cameron, H. C., and De Navasquez, S. (1936). Guys Hosp. Rep., 86,366 .

Eliasberg, H., and Neuland, W. (1920). Jb. Kinderheilk., 93, 88. Lliasberg, (1921). Ibid., 94, 102.

Engel, S. (1921). Berl. klin. Wschr., 58. 877.

Engel, S. (1921). Berl. klin. Wschr., 58. 877.

Fish, R. H., and Pagel, W. (1938). Path. Bact., 47, 593.
Graham, S., and Hutchison, J. H. (1947). Arch. Dis. Childh., 22, 162.

Hutchison, J. H. (1949). Quart. J. Med., 18, 21.
Jones, E. M., Rafferty, T. N., and Willis, H. S. (1942). Amer. Rev. Tuberc., 46, 392.

Kayne, G., Pagel, W., and O'Shaughnessy, L. (1948). Pulmonary Tuberculosis, 2nd ed. Oxford University Press, London.

Kent, E. M. (1942). Amer. Rev. Tuberc., 46, 524.

Lange, B. and Brunzema. D. (1930). Z. Hyg. InfektKr., 3, 354.

Langer, H. (1923). $Z$. Kinderheilk., 34, 142.

Lightwood, R, and Wilson. R. (1936). Arch. Dis. Childh., $2,321$.

Ligner, J. (1931). $Z$. Kinderheilk, 50, 505 . Quoted by Wallgren and Miller.

Lincoln, E. M., and Grethman, W. G. (i939) J. Pediat., 15, 62. Macgregor, A. R., and Alexander, W. A. (1937). Edinb. med. J., 44, 561 .

Macpherson, A. M., and Lutwyche, V. U. (1950). Thorax, 5, 1.

Martin, L. C., and Berridge, F. R. (1942). Lancet, 2, 327.

Morlock, H. V., and Pinchin, A. J. S. (1933). Lancet, 1, 1114.

Nichols, J. L. (1905). Med. News, N.Y., 87, 638.

Nichols, J. L. (1905). Med. News, N.Y. . 87, 638.

Pinner, M. (1945). Pulmonary Tuberculosis in the Adult. Thomas, Springfield, Illinois.

Reichle, H. S. (1933). Amer. J. Dis. Child., 45, 307.

Rich. A. R. (1944). The Pathogenesis of Tuberculosis. Thomas, Springfield, Illinois.

Richards, W. F. (1944a). Proc. roy. Soc. Med., 37, 589.

- (1944b). Tubercle, 25, 60

(1952). In Modern Practice in Tuberculosis, ed. Sellors, T H. (1952). In Modern Practice in Tuberculosis, ed. Sellors, T H., and Livingstone, J. L. Vol. 2, pp. 15-43. Butterworth,
Robbins, L. L., and Hale, C. H. (1945). Radiology, 45, 23.

Rubinstein, H.(1928). Beitr. Klin. Tuberk., 70, 773.

Seal, R. (1952). Personal communication.

Soulas, A., and Mounier-Kuhn, P. (1949). Bronchologie. Masson, Paris.

Spence, J. C. (1932). Arch. Dis. Childh. 7 , 1.

Wellgren A., and Miller, J. A. (1939). Pulmonary Tuberculosis in Adults and Children. Nelson, New York.

Willis, H. S. (1934). Amer. J. Roentgenol., 31, 721 